\title{
Obstetric hysterectomy: an emergency lifesaving procedure
}

\author{
Meena N. Satia*, Vibha More \\ Department of Obstetrics and Gynaecology, Seth G. S. Medical College and K.E.M. Hospital, Mumbai, Maharashtra, \\ India
}

Received: 18 May 2016

Accepted: 10 June 2016

*Correspondence:

Dr. Meena N. Satia,

E-mail: meenasatia@kem.edu

Copyright: (C) the author(s), publisher and licensee Medip Academy. This is an open-access article distributed under the terms of the Creative Commons Attribution Non-Commercial License, which permits unrestricted non-commercial use, distribution, and reproduction in any medium, provided the original work is properly cited.

\begin{abstract}
Background: Although rare in modern obstetrics, emergency peripartum hysterectomy (EPH) remains a life-saving procedure, in the event of uncontrollable postpartum hemorrhage. Observations regarding the causes and outcomes of EPH provide valuable insights relevant to the current management perspectives in obstetrics. This study is intended to assess the contemporary prevalence, indications, and outcomes of EPH, at a Tertiary care referral institute.

Methods: A descriptive observational study was conducted as a retrospective analysis of patient-records, over a span of 3 years January 2011-December 2013, in the department of obstetrics and gynecology, at the KEM hospital, in Mumbai. Cases of EPH were analyzed for information, maternal age, parity, gestational age, type of delivery, indications for EPH and outcomes of the procedure.

Results: The average annual incidence rate was 1 per 1000 deliveries. $44 \%$ of the cases had an indication of abnormal placentation. $60 \%$ of the cases had caesarean section deliveries. Multiparity, previous LSCS, and gestation period of $<37$ weeks, were the commonly observed associations. 52\% of cases required ICU admission. Maternal mortality rate was $8 \% .20 \%$ of the cases had intrauterine fetal death.

Conclusions: Abnormal placentation was evident as the leading cause of uncontrollable hemorrhage. This is possibly in view of a continual improvement in the management of uterine atony, reduced incidence of uterine rupture, and importantly, a rising trend of caesarean section delivery. This calls for more thoughtful considerations, regarding decisions for caesarean section delivery, in obstetrics practice.
\end{abstract}

Keywords: EPH, Caesarean, Multiparity

\section{INTRODUCTION}

Making a clinical decision for an emergency peripartum hysterectomy (EPH) is amongst the most difficult surgical dilemmas, faced by an obstetrician. The clinical judgment, on the spot, is a decisive choice between saving a mother's life and compromising on her reproductive capability. This is compounded by the unplanned nature of the surgery, and the patient's compromised status due to blood loss. Although rarely necessary in modern obstetrics, EPH remains an invaluable life-saving procedure, demanding a sound clinical judgment and precision.
$\mathrm{EPH}$ is a hysterectomy performed in the event of lifethreatening haemorrhage, during or immediately following abdominal or vaginal deliveries, and following the failure of all conservative measures of achieving haemostasis. Commonly encountered indications that necessitate EPH include uterine atony, abnormal placentation, or uterine rupture. Although traditionally, uterine atony has been the leading indication for EPH, recent studies do suggest an increasing trend of abnormal placentation, associated with more frequent Caesarean section deliveries. $^{1,2}$

Since the obstetrics practice trends may significantly influence the need and outcome of $\mathrm{EPH}$, a periodic 
monitoring of this evidence, would provide valuable insights for the current management practices in obstetrics. Such evidence from our country is limited, and restricted to specific territories. Moreover, the evidence from various small studies from India and South Asia, do not suggest a consistent picture. ${ }^{3-9}$ Timely decision and good surgical skills are the best components of this life saving surgery which amounts to near miss cases. A good team of anaesthetists and a well-equipped blood bank facility with round the clock availability of blood and blood products is needed to improve the worsening hemodynamic parameters and supports the patient to sustain the surgery.

The purpose of this study is to assess the contemporary prevalence, indications, and outcomes of $\mathrm{EPH}$, at a tertiary care referral institute, from the Maharashtra state of India.

\section{METHODS}

This is a descriptive observational study, conducted as a retrospective analysis of patient-records over 3 years, spanning from January 2011, till December 2013, within the department of obstetrics and gynecology, at the KEM hospital, in Mumbai, Maharashtra, India.

Records of all the patients, who underwent obstetric hysterectomies within this period, were reviewed. Cases of EPH were analyzed for information regarding the maternal age, parity, gestational age, type of delivery, indications for EPH, and outcomes of the procedure including intraoperative complications, length of hospital stay, amount of blood transfusion required, admission to intensive care unit, peripartum maternal and fetal morbidity, and mortality.

Descriptive statistics were used for the study. The frequency of EPH was reported in terms of average annual incidence rate per 1000 deliveries. Other details were reported in numbers and in percentages.

\section{RESULTS}

During the study period, out of 24811 deliveries, 25 cases of emergency peripartum hysterectomy were reported. Of the $25 \mathrm{EPH}$ cases, 8 cases were registered at the institute, whereas 15 cases were transferred from elsewhere, and 2 cases were unregistered. The average annual incidence rate is 1 per 1000 deliveries. Year-wise trends are summarized in Table 1.

Table 1: Frequency of EPH (2011-2013).

\begin{tabular}{|llll|}
\hline Year & Deliveries & EPH & $\begin{array}{l}\text { Annual incidence } \\
\text { (per 1000) }\end{array}$ \\
\hline 2011 & 7978 & 8 & 1.0 \\
\hline 2012 & 8271 & 6 & 0.7 \\
\hline 2013 & 8562 & 11 & 1.3 \\
\hline Overall & 24811 & 25 & 1.0 \\
\hline
\end{tabular}

The past obstetric history is summarized in Figure 1. Of the $25 \mathrm{EPH}$ cases, 23 cases had a history of multiparity, which included 17 cases of previous LSCS.

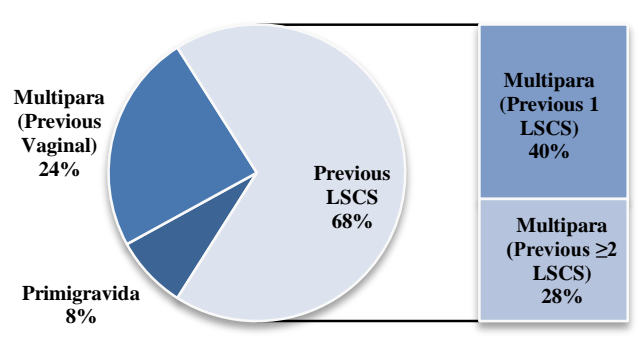

*LSCS: lower segment caesarean section

Figure 1: Previous obstetric history.

Of the $25 \mathrm{EPH}$ cases, 13 cases had a gestational age of $<37$ weeks, which included 8 cases of $<34$ weeks of gestation, and 5 cases with a gestational age of 34-37 weeks.

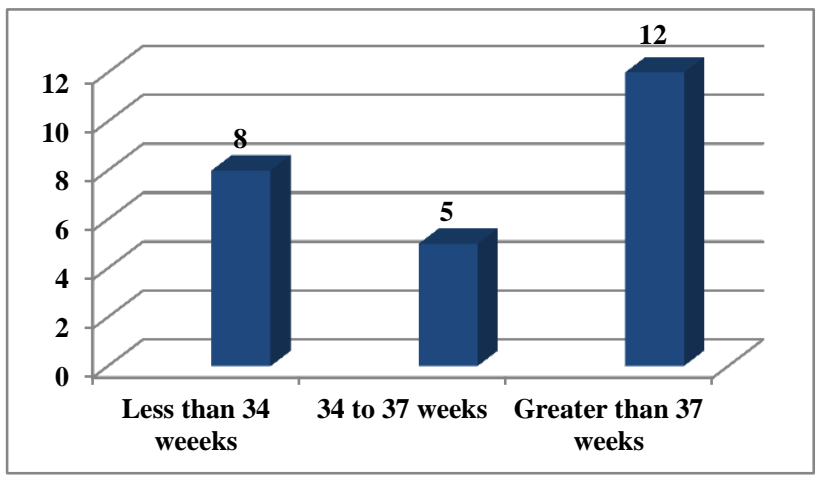

Figure 2: Gestational age and obstetric hysterectomy.

The indications for EPH surgeries are summarized in Figure 3. Of the $25 \mathrm{EPH}$ surgeries, 11 were required for abnormal placentation, including 7 for placenta previa (with placenta accreta, percreta or increta), and 4 for adherent placenta or bleeding from retained placenta. Atonic uterus accounted for 3 cases, and ruptured uterus, for 4 cases.

Regarding the mode of delivery for the current pregnancy, $18 \mathrm{EPH}$ surgeries (72\%) were performed following a Cesarean section, and 7 surgeries (28\%) following a vaginal delivery. Internal iliac ligation was also done in 5 cases, and balloon embolization was done in 2 cases.

Regarding the surgical complications, bladder injury was observed in 2 cases, disseminated intravascular coagulopathy in 3 cases, sepsis in 2 cases, acute renal failure in 2 cases, and hypovolemic shock in 4 cases. Blood transfusion was required for all the cases that survived. 
The outcomes of the $25 \mathrm{EPH}$ surgeries are summarized in Table 2.

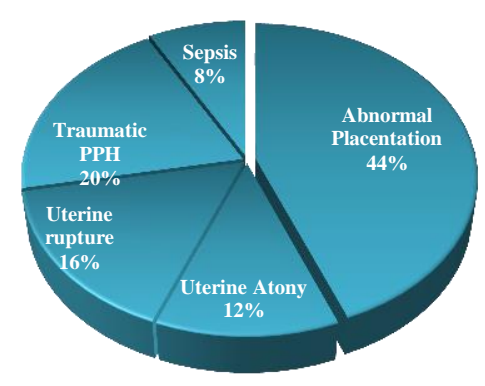

Figure 3: Indications for EPH.

Table 2: Outcomes of EPH surgeries.

\begin{tabular}{|ll|}
\hline Outcomes & Number of cases (\%) \\
\hline Maternal outcomes & \\
\hline Intensive care (total) & $17(68)$ \\
ICU admission & $13(52)$ \\
Need for ventilator support & $4(16)$ \\
\hline Transfusion of blood and blood products & $23(92)$ \\
\hline Maternal mortality & $2(8)$ \\
\hline Fetal outcomes & \\
\hline Live birth & $20(80)$ \\
With mother & $12(48)$ \\
NICU & $8(32)$ \\
\hline Intra uterine fetal death & $5(20)$ \\
\hline
\end{tabular}

\section{DISCUSSION}

The incidence of EPH is reported to vary from 0.24 to 8.9 per 1000 deliveries, as per a systematic review by Machado LSM et al. ${ }^{2}$ In another review of EPH risk in high income countries, the median incidence rate of EPH was observed to be 0.61 per 1000 deliveries, with a trend of increasing rate over time. ${ }^{1}$ Amongst the recently published studies from India, the reported incidence rates range from 0.83 to 3.9 per 1000 deliveries. ${ }^{5-9}$ The observations from our study are consistent with these findings, and suggest a relatively fair incidence rate; however, the number of surgeries required in 2013, was nearly two-fold higher as compared to the previous year. Of note, only a third of the cases were registered at the institute, the remaining being transferred from other centers. KEM hospital is a tertiary referral institute, which receives a substantial proportion of patients from Mumbai, the state of Maharashtra, and even from remaining parts of India. Although this contributes to the heterogeneity of the study population, this also represents the true national picture of a government setup more closely.

In our study, the majority of patients undergoing EPH had a history of multiparity. Multiparity is a known independent risk-factor for postpartum hemorrhage. ${ }^{2}$ The noteworthy finding was regarding the presence of a previous history of LSCS, in over two-thirds of the cases. This was also consistent with the observation of abnormal placentation, being the most common cause of EPH in our study. Abnormal placentation is increasingly being reported as the commonest indication for $\mathrm{EPH}$, surpassing the previous leading cause of uterine atony. ${ }^{1,2}$ The trend of increasing caesarean section deliveries, contributes to the increased risk of abnormal placentation. ${ }^{10}$ It is known from multiple studies, that caesarean section is associated with an increased risk of EPH. ${ }^{11-18}$ This was confirmed by a recent systematic review from de la Cruz et al. ${ }^{1}$ The authors identified that Caesarean section, either as a previous history or as the current mode of delivery, was strongly and consistently associated with an increased risk of EPH. ${ }^{1}$ Stanco et al. reported that $43.4 \%$ of their emergency hysterectomies were done because of uterine atony, while $33.9 \%$ were due to placenta previa with accreta ${ }^{19}$ A study from the same institution in 1993 stated that their primary indication was placenta accreta, the problem in $45 \%$ of cases, followed by uterine atony, with $20 \%$. Baskett reported that the main indications for hysterectomy were abnormal placentation $(50 \%)$ and atonic postpartum hemorrhage (32.8\%). ${ }^{20}$

Table 3: Comparative statistics.

\begin{tabular}{|c|c|c|c|}
\hline \multirow{3}{*}{$\begin{array}{l}\text { Uterine } \\
\text { atony }\end{array}$} & Other studies & Results & Our study \\
\hline & Stanco et al ${ }^{19}$ & $43.4 \%$ & \multirow{2}{*}{$48 \%$} \\
\hline & ${\text { Basket et } \mathrm{al}^{20}}^{20}$ & $32.8 \%$ & \\
\hline \multirow{2}{*}{$\begin{array}{l}\text { Abnormal } \\
\text { placentation }\end{array}$} & Stanco et al & $33.9 \%$ & \multirow{2}{*}{$34 \%$} \\
\hline & Basket et al & $50 \%$ & \\
\hline
\end{tabular}

In our study, the mode of delivery for the current pregnancy was caesarean section, in the majority of the cases. Moreover, the risk of EPH tends to increases with each successive Caesarean section delivery. ${ }^{15}$ These findings have significant practice-related implications, and merit a heightened awareness of these unwarranted major complications, amongst the obstetrician fraternity. Ensuring a sound judgment in opting for a caesarean section, and timely diagnosis and management of abnormal placentation, could help address this otherwise difficult complication to some extent.

In our study, more than half of the cases were associated with preterm labor. Preterm labor has also been to be associated with increased risk for EPH. ${ }^{21}$

EPH is associated with a high rate of complications. The need for blood transfusion, injury of the urinary tract, disseminated intravascular coagulopathy, or the need for re-exploration in view of uncontrolled bleeding, contribute to the increased rate of complications. In our study, the rate of complications was within the expected range for EPS. All the surviving patients required postoperative blood transfusion. 
In terms of outcomes, maternal mortality was observed in $8 \%$ of the EPH cases. This frequency is consistent with the maternal mortality reported in various Indian studies (0 to $17.7 \%))^{5-9}$ The frequency reported from developed countries ranges from $0-16.7 \%$, with an average rate of $3 \%$. Intrauterine fetal deaths occurred in one-fifth of the cases. Of the 25 cases, less than half of the babies were reasonably healthy, who did not require observation in the NICU. The frequency of perinatal mortality is observed to be consistently high in the Indian studies. ${ }^{5-9}$ Although this descriptive evidence may not suggest much regarding the possible improvements in our approach, it is always relevant to ensure high standards of maternal and fetal care, firstly to avoid this complication of postpartum hemorrhage as far as possible, and secondly, to ensure all possible measures for a successful salvage procedure, with minimal complications and more acceptable outcomes, compared to the current observations.

\section{CONCLUSION}

Obstetric hysterectomy is a lifesaving procedure and if this is achieved many more near miss cases can be salvaged. The outcome depends on timely decision, good clinical acumen and surgical expertise. Improvement in the health infrastructure and health education will go a long way in preventing such catastrophic events. Proper antenatal care, identification of high risk cases, patient counseling and referral to a tertiary care centre at an appropriate time can prevent the incidence of this disastrous event. Every obstetrician should master their skills and expertise to perform obstetric hysterectomy and thus can help in reducing the maternal morbidity and mortality.

\section{Funding: No funding sources}

Conflict of interest: None declared

Ethical approval: The study was approved by the Institutional Ethics Committee

\section{REFERENCES}

1. De la Cruz CZ, Thompson EL, O'Rourke K, Nembhard WN. Cesarean section and the risk of emergency peripartum hysterectomy in high-income countries: a systematic review. Arch Gynecol Obstet. 2015;292(6):1201-15.

2. Machado LSM. Emergency peripartum hysterectomy: incidence, indications, risk factors and outcome. N Am J Med Sci. 2011;3(8):358-61.

3. Nisar N, Sohoo NA. Emergency peripartum hysterectomy: frequency, indications and maternal outcome. J Ayub Med Coll Abbottabad. 2009;21(1):48-51.

4. Korejo R, Nasir A, Yasmin H, Bhutta S. Emergency obstetric hysterectomy. J Pak Med Assoc. 2012;62(12):1322-5.

5. Chawla J, Arora D, Paul M, Ajmani SN. Emergency obstetric hysterectomy: a retrospective study from a teaching hospital in North India over eight years. Oman Med J. 2015;30(3):181-6.

6. Mukherjee S, Agarwal L, Dahiya S, Amrin S, Singh P. A retrospective study of obstetric hysterectomy in a tertiary care hospital. Int J Med Sci Public Health. 2016;5(8):1-3.

7. Jayaram S, Varghese AP. A clinical review of obstetric hysterectomies done in medical college, Kottayam for a period of six years. Int J Reprod Contracept Obstet Gynecol. 2016;5(2):482-6.

8. Wani S, Fareed P, Gull Y, Mahajan N. Emergency peripartum hysterectomy: incidence, indications and fetomaternal outcome in a tertiary care hospital. IJCRR. 2016;8(3):7-10.

9. Kittur S, Swetha D. Emergency peripartum hysterectomy: a study in tertiary care centre and medical college in Hubli, North Karnataka, India. Int J Reprod Contracept Obstet Gynecol. 2016;5(4):1097-101.

10. Timor-Tritsch IE, Monteagudo A. Unforeseen consequences of the increasing rate of cesarean deliveries: early placenta accreta and cesarean scar pregnancy. A review. Am J Obstet Gynecol. 2012;207(1):14-29.

11. Knight M, Kurinczuk JJ, Spark P, Brocklehurst P. Cesarean delivery and peripartum hysterectomy. Obstet Gynecol. 2008;111:97-105.

12. Kwee A, Bots ML, Visser GH, Bruinse HW. Emergency peripartum hysterectomy: a prospective study in the Netherlands. Eur J Obstet Gynecol Reprod Biol. 2006;124:187-92.

13. Selo-Ojeme DO, Bhattacharjee P, Izuwa-Njoku NF, Kadir RA. Emergency peripartum hysterectomy in a tertiary Londonhospital. Arch Gynecol Obstet. 2005;271:154-9.

14. Stivanello E, Knight M, Dallolio L, Frammartino B, Rizzo N, Fantini MP. Peripartum hysterectomy and caesarean delivery: a population-based study. Acta Obstet Gynecol Scand. 2010;89:321-7.

15. Silver RM, Landon MB, Rouse DJ, Leveno KJ, Spong CY, Thom EA, et al. Maternal morbidity associated with multiple repeat cesarean deliveries. Obstet Gynecol. 2006;107:1226-32.

16. Bodelon C, Bernabe-Ortiz A, Schiff MA, Reed SD. Factors associated with peripartum hysterectomy. Obstet Gynecol. 2009;114:115-23.

17. Sheiner E, Levy A, Katz M, Mazor M. Identifying risk factors for peripartum cesarean hysterectomy. A population based study. J Reprod Med. 2003;48:6226.

18. Whiteman MK, Kuklina E, Hillis SD, Jamieson DJ, Meikle SF, Posner SF, et al. Incidence anddeterminants of peripartum hysterectomy. Obstet Gynecol. 2006;108:1486-92.

19. Stanco LM, Schrimmer DB, Paul RH, Mishell DR. Emergency peripartum hysterectomy and associated risk factors. American Journal of Obstetrics and Gynecology. 1993;168(3)879-83. 
20. Baskett TF. Emergency obstetric hysterectomy. Journal of Obstetrics and Gynaecology. 2003;23(4):353-5.

21. Jakobsson M, Tapper AM, Colmorn LB, Lindqvist PG, Klungsøyr K, Krebs L, et al. Emergency peripartum hysterectomy: results from the prospective Nordic Obstetric Surveillance Study (NOSS). Acta Obstet Gynecol Scand. 2015;94(7):745-54.

Cite this article as: Satia MN, More V. Obstetric hysterectomy: an emergency lifesaving procedure. Int J Reprod Contracept Obstet Gynecol 2016;5:2338-42. 